\title{
Clinical Correlates of Apathy in Patients Recently Diagnosed with Parkinson's Disease: The ANIMO Study
}

\author{
Esther Cubo $^{a}$ Julián Benito-León ${ }^{c-e}$ Carlos Coronell $^{f}$ Diana Armesto ${ }^{b}$ \\ on behalf of the ANIMO Study Group \\ ${ }^{a}$ Department of Neurology and ${ }^{b}$ Research Unit, Complejo Asistencial Universitario, Burgos, ${ }^{\text {cDepartment of }}$ \\ Neurology, University Hospital ' 12 de Octubre', dCentro de Investigación Biomédica en Red sobre Enfermedades \\ Neurodegenerativas (CIBERNED) and 'Department of Medicine, Faculty of Medicine, Complutense University, \\ Madrid, and ${ }^{\mathrm{f}}$ Medical Department, Boehringer Ingelheim, Barcelona, Spain
}

\section{Key Words}

Behavior · Parkinson's disease $\cdot$ Apathy $\cdot$ Nonmotor

symptoms

\begin{abstract}
Objective: Little is known about apathy in the early stages of Parkinson's disease (PD). We determined the clinical correlates of apathy in a large representative sample of patients recently diagnosed with PD (ANIMO study). Methods: PD patients, diagnosed within 2 years of inclusion, were recruited in 102 outpatient clinics situated in 82 populations throughout Spain. Apathy was quantified using the Lille Apathy Rating Scale (LARS). Clinical comparisons and correlations were performed using nonparametric tests. Regression analyses were used to test the association of clinical variables with apathy. Results: We recruited 557 PD patients (60.3\% men) with a mean age of $68.8 \pm 9.7$ years, and UPDRS motor score of $21.1 \pm 10.8$. Apathy only was diagnosed in 186 (33.4\%), and apathy and depression in 215 patients (38.6\%). Patients with higher comorbidity $(\mathrm{OR}=1.10,95 \% \mathrm{Cl} 1.01-1.20, \mathrm{p}=$ 0.001), motor impairment $(\mathrm{OR}=1.07,95 \% \mathrm{Cl} 1.03-1.10, \mathrm{p}<$ $0.0001)$, and lower education $(\mathrm{OR}=2.16,95 \% \mathrm{Cl} 1.21-3.85$, $\mathrm{p}=0.009$ ) had higher odds of having apathy, in contrast to
\end{abstract}

patients living in a rural environment $(\mathrm{OR}=0.35,95 \% \mathrm{Cl}$ $0.32-0.85, p=0.01)$, and left predominant PD motor laterality $(\mathrm{OR}=0.34,95 \% \mathrm{Cl} 0.13-0.88, \mathrm{p}=0.01)$. LARS scores were significantly correlated with UPDRS motor scores $\left(r_{s}=0.44\right.$, $p<0.001)$, predominantly with axial score $\left(r_{s}=0.43, p<\right.$ $0.001)$. Conclusions: In PD, apathy is a very common and disabling nonmotor symptom separable from depression. $\mathrm{Pa}$ tients living in a rural environment, with lower comorbidity and motor impairment, higher education background, and left predominant PD motor laterality are at lower risk of suffering from apathy.

Copyright $\odot 2012$ S. Karger AG, Basel

\section{Introduction}

Although Parkinson's disease (PD) is primarily a movement disorder, it is accompanied by various nonmotor symptoms, including psychiatric and behavioral problems. Cross-sectional studies suggest that nonmotor symptoms, especially apathy, frequently go unrecognized by clinicians and remain untreated [1], with important clinical consequences for patients and their families [2]. This relative lack of attention is not justified, because ap-

\section{KARGER}

Fax +41613061234 E-Mail karger@karger.ch www.karger.com

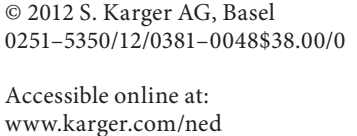

Dr. Esther Cubo

Complejo Asistencial Universitario, Neurology Department

Av. Cid 96

ES-09005 Burgos (Spain)

Tel. +34947281 922, E-Mail esthercubo@gmail.com 
athy is reported in $17-70 \%$ of PD patients [3], and has been associated with more severe cognitive dysfunction. In the clinical setting, apathy is characterized by lack of initiative and effort to perform everyday activities, lack of intellectual interest and initiative regarding personal or social issues, and indifference or flattening of affect [4]. Several authors have reported that apathy in PD can occur with or without depression, and may be associated with executive deficits, verbal memory impairment, bradyphrenia, and decreased global cognition [5].

Apathy is a topic that has only recently drawn scientific attention. Because little is known about the clinical correlates of apathy in patients recently diagnosed with $\mathrm{PD}$, we conducted a national multicenter cross-sectional survey of apathy, designed to examine the clinical correlates of apathy in this group of patients.

\section{Methods}

\section{General Study Design}

The study was designed as a cross-sectional survey. There were no treatment interventions during the course of this study. The ANIMO (Spanish word for 'good spirit') Group was formed in 2007 by a group of Spanish neurologists with expertise in PD [6]. We sampled a series of patients from 102 Spanish PD outpatient clinics from October 2008 to June 2009. These outpatient clinics were situated in 82 populations throughout Spain, therefore representing a broad geographic sampling. We chose these PD outpatient clinics because they maintain a computer-based registry of PD patients. In these computer-based registries, basic demographic data of the $\mathrm{PD}$ patients (e.g. age, gender) and clinical variables were recorded. We asked the participant neurologists to recruit a minimum of 6 consecutive PD patients who were coming to their clinic and who met the following criteria: PD diagnosed according to the United Kingdom Parkinson's Disease Society Brain Bank criteria [7], within 2 years of inclusion, and age $\geq 30$ years. Patients with other types of parkinsonism were excluded, as were those with dementia according to Diagnostic and Statistical Manual of Mental Disorders Fourth Edition, Text Revision (DSM-IV-TR) criteria [8]. A diagnosis of dementia was established on the basis of the medical history, an interview with the patient and a family member or caregiver, a general medical examination, results of laboratory tests, and diagnostic neuroimaging when needed. This study was approved by the Ethics Committee of 'Complejo Asistencial Universitario' in Burgos, Spain. All patients signed an informed consent before being enrolled.

\section{In Person Evaluation}

All assessments in each patient were performed on a single day by movement disorder neurologists. The presence and severity of motor impairment was assessed during the 'on state' using the motor subscale of the Unified Parkinson Disease Rating Scale (UPDRSm) [9], and the Hoehn and Yahr stage [10]. The UPDRSm provided the following scores: bradykinesia-rigidity score (sum of the bradykinesia plus rigidity items), tremor score (sum of the postural and rest tremor items), axial score (sum of the gait, postural stability, facial expression, and speech items), and total score [11]. We also asked the neurologists to supply medical information related to these patients, including age, gender, educational level, marital status, environment (urban vs. rural area), employment status, and medications. Comorbidity was assessed using the Cumulative Illness Rating Scale-Geriatrics (CIRS-G) [12], in which higher scores are associated with greater comorbidity. Individuals received a clinical psychiatric interview [13], with current and past psychiatric diagnoses established according to the DSM-IV-TR using the Structured Clinical Interview for DSM-IVTR Axis I Disorders. Diagnoses of symptomatic depression included major depressive episode, minor depression, and dysthymia. Depressive disorders in full remission (asymptomatic) were classified as non-depressed.

Apathy was evaluated using the Lille Apathy Rating Scale (LARS) [14]. This physician-administered scale was developed to ascertain and quantify apathy in the month prior to the assessment. LARS has been validated in individuals with PD with and without dementia, and categorizes the severity of apathy into 1 of 4 categories (absent, mild, moderate and severe apathy) [14]. LARS is based on a structured interview and includes 33 items divided into 9 domains, including reduction in everyday productivity; lack of interest; lack of initiative; extinction of novelty seeking and motivation; blunting of emotional responses; lack of concern; poor social life, and extinction of self-awareness [14]. Standard validity indices showed that the LARS is sensitive and capable of distinguishing between apathy and depression [14]. Global LARS scores range from -36 to +36 , with higher scores indicating greater apathy $[14,15]$. Apathy was defined here as a score on the LARS $\geq-22$ [14]. Missing LARS data were imputed by individual mean method if the missing data were $\leq 20 \%$ of total.

\section{Statistical Analysis}

Statistical analyses were performed with the Statistical Package for the Social Sciences (version 19.0; IBM SPSS, Statistics). All tests were two-tailed and significance was accepted at the $5 \%$ level $(\alpha=0.05)$. None of the continuous variables were normally distributed, thus nonparametric tests (Mann-Whitney U test, Kruskal-Wallis test, Spearman's rho) were used. Categorical variables were compared using the $\chi^{2}$ and Cramer's V tests. As most of the patients on dopaminergic agonists were receiving pramipexole, with fewer on ropinirole and rotigotine, these patients were considered as a single group (dopaminergic agonists). Patients were grouped according to the binary clinical diagnosis of apathy, in apathetic (LARS score $\geq-22$ ), nonapathetic (LARS score $<-22$ ), and clinical diagnosis of depression. Based on the presence of apathy and coexisting depression, patients were classified into four clinical groups: apathy only, patients with apathy and depression, depression only and free of apathy or depression (FAD). For multinomial logistic regression analysis, adjusted models were developed in which we considered the four clinical groups as the dependent variable, and all variables that were significantly associated with apathy or depression in univariate analysis $(\mathrm{p}<0.10)$ as predictor variables. These analyses generated odds ratio (OR) with $95 \%$ CI. A separate stepwise linear regression analysis was also conducted to examine the relationship between clinical and sociodemographic variables and LARS total score as the dependent variable. 
Table 1. Clinical and demographic characteristics of cohort $(\mathrm{n}=$ 557)

\begin{tabular}{lc}
\hline Characteristics & \\
\hline Mean age \pm SD, years (median) & $68.8 \pm 9.7(70.0)$ \\
Male gender & $336(60.3 \%)$ \\
Educational level & \\
$\quad$ Illiterate & $38(6.8 \%)$ \\
$\quad$ Primary studies & $350(62.8 \%)$ \\
$\quad$ Secondary or higher studies & $167(30.0 \%)$ \\
$\quad$ Unknown & $2(0.4 \%)$ \\
Geographical area & \\
$\quad$ Rural area & $197(35.3 \%)$ \\
$\quad$ Urban area & $360(64.6 \%)$ \\
Mean PD duration \pm SD, years (median) & $1.3 \pm 0.6(1)$ \\
Median Hoehn and Yahr stage (range) & $1.5(1-4)$ \\
Mean UPDRSm score \pm SD (median) & $21.1 \pm 10.8(19)$ \\
Depression & $250(44.8 \%)$ \\
$\quad$ Major depression & $31(12.4 \%)$ \\
$\quad$ Minor depression & $161(64.4 \%)$ \\
$\quad$ Dysthymia & $58(23.2 \%)$ \\
Mean LARS score \pm SD (median) & $-12.4 \pm 14.4(-16)$ \\
Dopaminergic agonists use & $357(64.1 \%)$ \\
Levodopa use & $332(59.6 \%)$ \\
Antidepressants use & $235(42.2 \%)$ \\
\hline
\end{tabular}

Frequency (\%) is reported.

\section{Results}

Of the 677 PD patients who were deemed eligible for the study, 557 (82.3\%) were finally chosen. The remaining 120 (17.7\%) PD patients were excluded due to insufficient medical information (e.g. missing values on one or more UPDRS items). We compared the final sample of 557 cases to the 120 cases with insufficient medical information and they were similar in terms of age $(68.8 \pm 9.7$ vs. 67.7 \pm 9.4 years, Mann-Whitney, $\mathrm{p}=0.14)$ and gender $(336$ [60.3\%] vs. 67 [55.8\%] men, $\chi^{2}$ test, $p=0.41$ ). Imputation for missing data of the LARS was carried out in $47 \mathrm{sub}$ jects ( $8.4 \%$ of the final sample). The $557 \mathrm{PD}$ patients were recruited between March 2007 and January 2009.

Sociodemographic and clinical characteristics of patients are listed in table 1. One hundred and eighty-six patients (33.4\%) were diagnosed with apathy only, $215 \mathrm{pa-}$ tients (38.6\%) were diagnosed with apathy and depression, 35 patients $(6.3 \%)$ were diagnosed with depression only, and 121 patients (21.7\%) were FAD. Apathy was more frequently diagnosed as severe in patients diagnosed with minor depression compared to patients with major depression $\left(\chi^{2}\right.$ test, $\left.\mathrm{p}<0.001\right)$. Clinical and treatment characteristics are reported in table 2 .

Table 2. Demographic and clinical characteristics comparison

\begin{tabular}{|c|c|c|c|c|c|}
\hline & $\begin{array}{l}\text { Apathy only } \\
(\mathrm{n}=186)\end{array}$ & $\begin{array}{l}\text { Apathy and de- } \\
\text { pression }(n=215)\end{array}$ & $\begin{array}{l}\text { Depression only } \\
(\mathrm{n}=35)\end{array}$ & $\begin{array}{l}\text { No apathy or de- } \\
\text { pression }(\mathrm{n}=121)\end{array}$ & $\mathrm{p}$ value \\
\hline Mean age $\pm S D$, years (median) & $69.9 \pm 9.6(71.0)$ & $69.8 \pm 8.8(71.0)$ & $66.6 \pm 9.0(68.0)$ & $66.0 \pm 10.9(67.0)$ & 0.004 \\
\hline Male gender (\%) & $117(62.9)$ & $129(60.0)$ & $14(40.0)$ & $76(62.8)$ & 0.07 \\
\hline Secondary studies or higher (\%) & $46(25.0)$ & $54(25.1)$ & $19(54.3)$ & $48(39.7)$ & $<0.0001$ \\
\hline Married or cohabitant (\%) & $137(73.7)$ & $144(67.0)$ & $26(76.5)$ & $95(78.5)$ & 0.12 \\
\hline Employee (\%) & $25(13.4)$ & $27(12.6)$ & $6(17.1)$ & $30(24.8)$ & 0.02 \\
\hline Urban area $(\%)$ & $129(69.4)$ & $136(63.3)$ & $26(74.3)$ & $69(57.0)$ & 0.09 \\
\hline Mean UPDRSm score \pm SD (median) & $20.9 \pm 9.8(19.0)$ & $24.8 \pm 12.0(24.0)$ & $15.6 \pm 9.1(14.0)$ & $16.5 \pm 7.7(15.0)$ & $<0.0001$ \\
\hline Mean LARS score \pm SD (median) & $-10.0 \pm 8.8(-12.0)$ & $-3.1 \pm 13.9(-2.0)$ & $-27.8 \pm 3.4(-27.0)$ & $-27.8 \pm 3.7(-27.0)$ & $<0.0001$ \\
\hline \multicolumn{6}{|l|}{ PD laterality (\%) } \\
\hline Right & $87(46.8)$ & $118(54.9)$ & $21(60.0)$ & $64(52.9)$ & 0.001 \\
\hline Left & $77(41.4)$ & $57(26.5)$ & $12(34.3)$ & $50(41.3)$ & \\
\hline Both & $22(11.8)$ & $40(18.6)$ & $2(5.7)$ & $7(5.8)$ & \\
\hline Dopaminergic agonists use (\%) & $119(64.0)$ & $147(68.4)$ & $22(62.9)$ & $69(57.0)$ & 0.22 \\
\hline Levodopa use (\%) & $114(61.3)$ & $141(65.6)$ & $21(60.0)$ & $56(46.3)$ & 0.006 \\
\hline Antidepressants use (\%) & $77(41.4)$ & $124(57.7)$ & $25(71.4)$ & $9(7.4)$ & $<0.0001$ \\
\hline Mean CIRS-G score \pm SD (median) & $4.3 \pm 3.4(4.0)$ & $5.1 \pm 3.5(4.0)$ & $3.0 \pm 2.6(3.0)$ & $3.4 \pm 2.8(3.0)$ & 0.001 \\
\hline
\end{tabular}

Kruskal-Wallis test and Cramer's V tests were used for comparisons. 
In terms of apathy, LARS scores were significantly higher among patients on antidepressants compared to patients not taking antidepressants $(-5.63 \pm 15.12$ vs. $-17.35 \pm 11.66$, Mann-Whitney test, $\mathrm{p}<0.0001)$. As we can see from table 2, compared to other groups, patients diagnosed with apathy only were older, less educated, and with a trend toward having a higher proportion of males. Instead, patients diagnosed with apathy and depression had more severe motor and apathy impairment, higher comorbidity, higher use of levodopa, lower rate of employees, and higher proportion of patients classified as having symmetric PD. In contrast, patients diagnosed with depression only were predominantly women, had a higher education background, lower comorbidty, and higher proportion with predominant right PD. Finally, FAD patients had the lowest proportion of levodopa use, symmetric PD, the highest rate of employees and less severe motor impairment. In the multinomial logistic regression model (table 3), the following variables were included: age, gender, predominant motor PD laterality, education, rural versus urban environment, employment status, levodopa use and UPDRSm and CIRS-G scores, as the independent variables, and apathy and depression status as the dependent variable. Compared to the FAD group, higher scores of the UPDRSm and lower education were associated with higher odds of having apathy only, and apathy with depression. Instead, higher scores of comorbidity were associated with higher odds of having apathy and depression. On the contrary, rural environment and predominant left PD motor impairment were associated with lower odds of having apathy only, and apathy and depression, respectively. Males were associated with lower odds of having depression only.
In the stepwise linear regression, the following variables were included: age, gender, education, marital and employment status, UPDRSm score, predominant motor PD laterality, dopaminergic treatment, CIRS-G score, and clinical diagnosis as the independent variables and the LARS scores as the dependent variable. Forty-four percent of the variance of the LARS scores were explained by the clinical diagnosis of apathy and depression (standardized $\beta=0.46, t=-13.83, p<0.0001)$, UPDRSm scores (standardized $\beta=0.28, \mathrm{t}=9.03, \mathrm{p}<0.0001$ ), CIRS-G scores (standardized $\beta=0.13, t=3.73, p<0.0001$ ), dopaminergic treatment (standardized $\beta=0.07, \mathrm{t}=2.37, \mathrm{p}=$ 0.01 ), and marital status (standardized $\beta=0.09, \mathrm{t}=2.83$, $\mathrm{p}=0.005$ ).

In univariate analysis, there were significant correlations between the LARS scores and UPDRSm scores $\left(r_{s}=\right.$ $0.44, \mathrm{p}<0.001)$, predominantly with the axial $\left(\mathrm{r}_{\mathrm{s}}=0.43\right.$, $\mathrm{p}<0.001)$ and bradykinesia-rigidity $\left(\mathrm{r}_{\mathrm{s}}=0.38, \mathrm{p}<0.001\right)$ UPDRSm subscales, and moderate with the tremor UPDRS subscale $\left(\mathrm{r}_{\mathrm{s}}=0.21, \mathrm{p}<0.001\right)$. Axial and bradykinesia-rigidity-UPDRSm scores were significantly higher in patients with apathy and depression compared to patients with depression only and FAD (table 4).

\section{Discussion}

In this large multicenter nationwide cross-sectional study, we found a similar prevalence of apathy compared to other studies including incident PD and more advanced PD cases [5, 16-18]. The results of this study have several clinical implications. First, prior reports are inconsistent about the prevalence of apathy and frequent overlapping of apathy and depression $[19,20]$. In our

Table 3. Odds of clinical and sociodemographic characteristics based on apathy and depression status (dependent variable)

\begin{tabular}{|c|c|c|c|c|c|c|}
\hline & \multicolumn{2}{|c|}{ Apathy only $(\mathrm{n}=186)$} & \multicolumn{2}{|c|}{ Apathy and depression $(\mathrm{n}=215)$} & \multicolumn{2}{|c|}{ Depression only $(\mathrm{n}=35)$} \\
\hline & OR (95\% CI) & $\mathrm{p}$ value & OR (95\% CI) & $\mathrm{p}$ value & OR (95\% CI) & $\mathrm{p}$ value \\
\hline UPDRSm & $1.04(1.01-1.07)$ & 0.005 & $1.07(1.03-1.10)$ & $<0.0001$ & - & \\
\hline CIRS-G score & - & & $1.10(1.01-1.20)$ & 0.001 & - & \\
\hline Lower education & $2.16(1.21-3.85)$ & 0.009 & $2.10(1.17-3.76)$ & 0.01 & - & \\
\hline Rural area & $0.52(0.32-0.85)$ & 0.01 & - & & - & \\
\hline PD laterality (left) & - & & $0.34(0.13-0.88)$ & 0.002 & - & \\
\hline Male gender & - & & - & & $0.32(0.14-0.73)$ & 0.01 \\
\hline
\end{tabular}

Adjusted for age, employment status, and levodopa use.

The reference category was the group of patients free of apathy and depression. 
Table 4. UPDRS motor domains scores and apathy-depression status

\begin{tabular}{llll}
\hline & $\begin{array}{l}\text { Axial } \\
\text { mean } \pm \text { SD (median) }\end{array}$ & $\begin{array}{l}\text { Bradykinesia-rigidity } \\
\text { mean } \pm \text { SD (median) }\end{array}$ & $\begin{array}{l}\text { Tremor } \\
\text { mean } \pm \text { SD (median) }\end{array}$ \\
\hline Apathy only $(\mathrm{n}=186)$ & $4.17 \pm 2.70(4)$ & $13.22 \pm 6.67(12.50)$ & $3.51 \pm 2.89(3)$ \\
Apathy and depression $(\mathrm{n}=215)$ & $5.04 \pm 3.24(5)$ & $15.60 \pm 7.57(15)$ & $4.13 \pm 3.54(3)$ \\
Depression only $(\mathrm{n}=35)$ & $3.28 \pm 3.07(3)$ & $10.08 \pm 6.04(9.00)$ & $2.25 \pm 1.99(2)$ \\
No depression or apathy $(\mathrm{n}=121)$ & $2.77 \pm 2.04(3)$ & $10.72 \pm 5.45(10)$ & $3.04 \pm 2.44(3)$ \\
\hline Comparison $^{*}$, p value & $<0.0001$ & $<0.0001$ & 0.007 \\
\hline
\end{tabular}

* Kruskal-Wallis test.

study, in agreement with another study [21], we found that apathy and depression may be separable in $\mathrm{PD}$, and each nonmotor symptom is associated with distinctive clinical features. Interestingly, apathy was more severe when it coexisted with depression and in patients taking antidepressants.

Second, in contrast to depression, apathy was significantly associated with more severe motor symptoms in agreement with other studies [5,17,21]. This discrepancy with the literature associating depression and PD [22] is likely explained by the bias of the small size of this particular group in our study. Third, when the UPDRS (nontremor, axial and bradykinesia/rigidity items) was analyzed separately, nontremor dominant symmetric PD was associated with apathy and coexisting depression indicating most likely a more rapid disease progression [23, 24]. However, a practical disadvantage of the cross-sectional approach of our study is the fact that the diagnosis of 'symmetric PD' may change to other forms of parkinsonism during follow-up. Likewise, older patients were more frequently diagnosed with apathy. It has been reported that higher age at onset is the most important factor for predicting greater motor impairment and nonmotor symptoms [25]. Therefore, apathy may be a sign of disease progression in PD [5], but longitudinal studies are needed to investigate exact relationships.

Fourth, interestingly, we observed that patients with left predominant PD motor symptoms (representing right hemisphere pathology) had lower odds of having apathy and depression compared to predominant PD left hemisphere pathology. It is well known that the motor symptoms of PD are mainly due to progressive asymmetric degeneration of nigral dopaminergic neurons [26]. Since this is an observational study, we cannot preclude more conclusions, but it seems that the PD left hemisphere may be dominant in mood and apathy, in contrast to previous findings, where apathy was a prominent feature of a dysfunction in the right prefrontal pathway [27].

Fifth, gender seems to influence depression in neurologic illness. We observed that depression was more frequent in females, in agreement with other studies [22]. Understanding how gender influences depression in neurologic illness and its response to treatment is a necessary step to improve the specificity of psychiatric treatment for depression [28]. Sixth, of note, we found that patients without apathy and depression remained employees. Likewise, living in a rural environment and higher education background were associated with lower odds of having apathy. The design of this study does not allow us to explain these results, but at least remarks the importance of the association of lifestyle, environment, and education with apathy. On the contrary, higher comorbidity influenced the manifestation of apathy and depression.

This study has several limitations. Although we excluded patients with dementia, we recognize that there is a lack of information regarding the cognitive status, especially mild executive dysfunction in our sample, which may have contributed to our results. Likewise, the design of our study did not enable us to establish the biochemical basis of apathy or depression. Reports in the literature suggest that apathy may be linked to ventral striatum and mesolimbic dopaminergic denervation [29]. As a matter of debate, dopaminergic treatments could potentially have a confounding effect on this aspect of the disease [4]. We found that apathy with or without associated depression was associated with a higher use of levodopa. This association may be likely due to the higher needs of dopaminergic medication in patients with more severe and predominant axial motor symptoms.

There are also certain factors that may confound the interpretation of our results, such as the confounding in- 
fluence of depression on the performance of apathy rating scales. Concomitant apathy and depression was detected in $38.6 \%$ of our PD sample, and the LARS scores were worse when apathy coexisted with depression. Although we recognize it can be criticized, LARS has shown good discriminant validity between apathy and depression by the original developers of the scale [14]. In fact, in our study, apathy was not directly associated with the severity of depression according to the DSM-IV TR classification [8], and LARS scores were similar between the group of patients diagnosed with depression only, and the FAD group [14], indicating that depression did not significantly impact on LARS scores. Overall, this study involved the analysis of cross-sectional data which precludes conclusions about the direction of causality. In effect, we cannot establish if there was a sample selection bias (patients volunteered to participate in this study), which may have led to an underestimation of the prevalence of apathy in PD. However, we recruited a large representative cross-section of the community-dwelling population of nondemented Spanish patients recently diagnosed with PD patients. In Spain, healthcare is fully state-subsidized, and community-dwelling PD subjects are mostly seen by hospital-based and hospital-associated neurologists [30]. There is no doubt that the use of a crosssectional design leaves us more susceptible to confounding variables; however, it also enables us to generate hypotheses that should be confirmed in further studies. This study also has several strengths. First, we attempted to adjust for the effects of many potential confounders and classified patients based on their apathy status and coexistence with depression. Second, as a matter of debate as well, we used modern statistical methods to deal with the challenge of missing data of the LARS [31]. People with worse apathy scores tend to be the persons with missing data. Hence excluding them would have provided artificially better mean scores. However, other authors have reported that the imputation of missing data can also result in biased conclusions [32]. Third, we determined the clinical correlates of apathy in a population of patients recently diagnosed with PD patients already on treatment. This avoided bias of treatment status on apathy status. Our results may therefore be extrapolated to the PD community to some degree.

In conclusion, apathy with or without coexisting depression is a common and disabling nonmotor symptom in patients recently diagnosed with PD. Patients with PD and lower education, living in a urban environment and with more severe motor impairment (especially axial signs) and comorbidity, are at risk of having apathy and depression. Instead, women with PD are at higher risk of having depression. Further studies are required to investigate the efficacy of pharmacological and nonpharmacological treatments of these currently under-recognized aspects of PD.

\section{Disclosure Statement}

The authors declare that there are no conflicts of interest and no competing financial interests.

\section{Acknowledgments}

The ANIMO was supported by an educational grant from Boehringer Ingelheim Spain.

The authors gratefully acknowledge the vital help of the other members of the ANIMO Study Group: Rosa Rodríguez-Fernández (Orense Hospital Complex, Orense, Orense); Robustiano Pego-Reigosa and José Manuel Paz-González (Calde General Hospital, Lugo, Lugo); Ernesto Cebrián-Pérez and Paula SuarezGil (Pontevedra Hospital Complex, Pontevedra); José MareyLópez, Enrique Corredera-García, Francisco Javier LópezGonzález, Xiana Rodríguez-Osorio and Susana Arias-Rivas (Santiago de Compostela University Hospital Complex, Santiago de Compostela, La Coruña); Ma Carmen Lema (La Coruña Hospital Complex, La Coruña, La Coruña); Joaquín Peña (Hospital 'San Agustín', Avilés, Asturias); Esther Suarez (Jove Hospital, Gijón, Asturias); Dulce Ma Solar-Sánchez (Cabueñes Hospital, Gijón, Asturias); José Antonio Vidal-Sánchez (Hospital 'Valle del Nalón', Langreo, Asturias); Alberto Bergareche (Bidasoa Hospital, Fuenterrabía, Guipúzcoa); Javier Ruiz (Donostia Hospital, San Sebastián, Guipúzcoa); Juan Carlos Gómez-Esteban and José Manuel Losada (University Hospital 'de Cruces', Bilbao, Vizcaya); José Manuel Fernández-García and Luis Carlos Álvaro-González (Basurto Hospital, Bilbao, Vizcaya); José Luis Sánchez-Menoyo and Javier Ruiz-Oseda (Galdakao Hospital, Galdakao, Vizcaya); Gerardo J. Soriano (Navarra Hospital, Pamplona, Navarra); María Martín-Bujanda (University Hospital 'Virgen del Camino', Pamplona, Navarra); Ángel Fernández-Díaz (Hospital 'El Bierzo', Ponferrada, León); Manuel A. Mazabel-Flores (Obra Hospitalaria 'Nuestra Señora de Regla', León); Oscar Llamazares de La Fuente ('San Francisco' Clinic, León); María Dolores Sevillano and Jesús Arcaya (Salamanca University Hospital, Salamanca, Salamanca); Ana Belén Caminero (Hospital 'Nuestra Señora de Sonsoles', Ávila, Ávila); Wadih Bowakim (University Hospital 'Río Hortega', Valladolid, Valladolid); Oscar Vega-López (Red Cross Central Hospital 'San José y Santa Adela', Madrid, Madrid); Ma José Catalán, Javier del Val and Rocío García-Ramos (University Clinic Hospital 'San Carlos', Madrid, Madrid); Esteban Francisco-Peña (La Moraleja Sanitas Hospital, Madrid, Madrid); Pedro Emilio Bermejo and Manuel Lara (University Hospital 'La Paz', Madrid, Madrid); Mireya Losada and Lydia López-Manzanares (University Hospital 'La Princesa', Madrid, Madrid); Alberto Esquivel (Hospital 'Infanta Leonor', Madrid, Madrid); Ignacio J. Posada, José Antonio Molina-Arjona, and Jerónimo Almajano (University Hospital '12 de Octubre', Madrid, Madrid); Mireya Losada 
López (Henares Hospital, Coslada, Madrid); Marina Mata and Pilar Sánchez-Alonso (University Hospital 'Puerta del Hierro', Majadahonda, Madrid); David Andrés Pérez and Loreto Ballesteros (Hospital 'Infanta Cristina', Parla, Madrid); Inmaculada Puertas (University Hospital 'Príncipe de Asturias', Alcalá de Henares, Madrid); José Jesús Balseiro (Getafe University Hospital, Getafe, Madrid); Fernando Alonso-Frech (Fuenlabrada University Hospital, Fuenlabrada, Madrid); María del Mar Morín and José Miguel Velázquez-Pérez (Hospital 'Virgen de la Salud', Toledo, Toledo); José Manuel Fernández-Carril (Guadalajara University Hospital, Guadalajara, Guadalajara); Marta Recio-Bermejo (General Hospital 'De la Mancha Centro', Alcázar de San Juan, Ciudad Real); Ramón Ibáñez and Julia Vaamonde (Ciudad Real General Hospital, Ciudad Real, Ciudad Real); Jorge Artal (University Hospital 'Miguel Servet', Zaragoza, Zaragoza); Elena López-García (University Clinic Hospital 'Lozano Blesa', Zaragoza, Zaragoza); Daniel Segarra (Alcañiz Hospital, Alcañiz, Teruel); Laura González-Mera (Viladecans Hospital, Viladecans, Barcelona); Jorge Hernández-Vara (Mutua de Terrassa Hospital, Terrassa, Barcelona); Ana Ma Jaén-Peraire (Game Medical Center, Sant Boi de Llobregat, Barcelona); Lourdes Ispierto-González and Laura Dorado-Bovix (Badalona Municipality Hospital, Badalona, Barcelona); José Ma Soler (Hospital Sant Bernabé, Berga, Barcelona); Alfonso Moral and Elisabeth Franquet-Gómez (Hospital 'Sant Camil', San Pedro de Ribas, Barcelona); Teresa Bernal (MIPS Private Foundation, Igualada, Barcelona); Tania Delgado (Hospital 'Parc Taulí', Sabadell, Barcelona); Matilde Calopa (Bellvitge University Hospital 'Princeps d'Espanya', L'Hospitalet de Llobregat, Barcelona); Juan Bello-López (L'Hospitalet General Hospital, L'Hospitalet de Llobregat, Barcelona); Carlos Oliveras-Ley (University Hospital 'del Mar', Barcelona); Vicente Jesús García-Gil (CAP Quevedo, Barcelona); Antonio Palasí, Oriol de Fabregues, and Antonio Callen (University Hospital 'Vall d'Hebron', Barcelona, Barcelona); Berta Pascual-Sedano (University Hospital 'Sant Pau', Barcelona); Albert Lladó Plarrumani, and Yolanda Blanco (University Clinic Hospital, Barcelona, Barcelona); Ana Malagelada (Barcelona Neurological Institute, Barcelona); Cesar Castejón ('Sagrada Familia' Clinic, Barcelona, Barcelona); Alain Luna-Rodríguez (Palamós Hospital, Palamós, Gerona); Raúl Martínez-Fernández, and Olga Carmona (Figueras Hospital, Figueras, Gerona); Fabián Márquez (Hospital 'Sant Jaume', Olot, Gerona); Josep M. Olivé Plana (San Juan University Hospital, Reus, Tarragona); Francisco Purroy-García (University Hospital 'Arnau de Vilanova', Lérida, Lérida); Juan José Baiges-Octavio (Tortosa Hospital 'Verge de la Cinta', Tortosa, Tarragona); Jesús Vega and Verónica González (Hospital 'Ciudad de Jaén', Jaén, Jaén); Carlos Sánchez-Ortiz and Fernando Sánchez-López (University Hospital 'Reina Sofía', Córdoba); Víctor M. Campos (Xanit International Hospital, Benalmádena, Málaga); Francisco Pérez (University Clinic Hospital 'Virgen de la Victoria', Málaga, Málaga); Fernando Vázquez ('Del Poniente' Policlinic, El Ejido, Almería); Juan Jesús Rodríguez (Instituto Especialidades Neurológicas-Virgen Rocío, Sevilla); Francisco Villalobos and Manuel Carballo (University Hospital 'Virgen del Rocío', Sevilla, Sevilla); José Manuel García-Moreno, Ma Dolores Morales-Martínez, and Jorge Patrignani-Ochoa (University Hospital 'Virgen de la Macarena', Sevilla, Sevilla); Francisca Terriza (Hospital 'Santa María del Puerto’, El Puerto de Santa María, Cádiz); Juan José Asencio (Puerto Real University Hospital, Puerto Real, Cádiz); Carmen García, Francisco Delgado-López, and Nuria Rodríguez-Fernán- dez (Jerez Hospital, Jerez de la Frontera, Cádiz); Francisco Escamilla and María José Pérez-Navarro (University Hospital 'Virgen de las Nieves', Granada); Fernando Castellanos and Bernardo Cueli (Hospital 'Virgen del Puerto', Plasencia, Cáceres); Montserrat Gómez (Hospital 'San Pedro de Alcántara', Cáceres, Cáceres); José María Ramírez-Moreno (University Hospital 'Infanta Cristina', Badajoz, Badajoz); Joaquín Gómez-Espuch (University General Hospital 'Morales Meseguer', Murcia); Ma Purificación Salmerón and José Manuel Rodríguez (University General Hospital 'Reina Sofia', Murcia, Murcia); Ossama Morsi-Hassan and José Eustasio Meca-Lallana (University Hospital 'Virgen de la Arrixaca', Murcia, Murcia); Sebastián Martín-Balbuena (Cieza Hospital Foundation, Cieza, Murcia); Eva Fages-Caravaca (University Hospital 'Santa María del Rosell', Cartagena, Murcia); Antonio Candeliere-Merlicco (Hospital 'Rafael Méndez', Lorca, Murcia); Ayoze González-Hernández and José A. Suarez-Muñoz (Grand Canary University Hospital 'Dr Negrín', Las Palmas de Gran Canaria, Islas Canarias); José Motias-Arbelo, University Hospital 'Insular Gran Canaria', Las Palmas de Gran Canaria, Islas Canarias); Francisco Javier Carrillo-Padilla (Canary Islands University Hospital, Tenerife, Islas Canarias); Jesús Norelis Lorenzo-Brito (University Hospital 'Nuestra Señora de Candelaria', Santa Cruz de Tenerife, Islas Canarias); Juan Manuel Callejo-Domínguez (Hospital 'Vega Baja Orihuela', Orihuela, Alicante); Ma José Sáenz (Elche University General Hospital, Elche, Alicante); Vicente Medrano-Martínez (Elda General Hospital, Elda, Alicante); $M^{a}$ Dolores Castaño Pérez (San Juan University Hospital, San Juan de Alicante, Alicante); Gema Mas-Sesé (Marina Baixa-Villajoyosa Hospital, Villajoyosa, Alicante); María José MonzónMinguillod (Requena Hospital, Requena, Valencia); Antonio Salvador-Aliaga, Dolores Alonso Salvador, and Vicente Peset-Mancebo (Valencia University Clinic Hospital, Valencia, Valencia); Carlos Perla-Muedra and Caridad Valero-Merino (University Hospital 'Arnau de Vilanova', Valencia, Valencia); Pilar TabernerAndres (University Hospital 'Dr. Peset', Valencia, Valencia); Emilio Meneu-García (La Plana Hospital, Castellón de la Plana, Castellón de la Plana); Elena Pajarón and Berta Claramonte Clausell (Castellón General Hospital, Castellón de la Plana, Castellón de la Plana); Fritz Nobbe (Juaneda Clinic, Palma de Mallorca, Palma de Mallorca); Jorge Eloy Elices-Palomar (Rotger Clinic, Palma de Mallorca, Palma de Mallorca); and Antonio García Trujillo (Neurologic Center, Palma de Mallorca, Palma de Mallorca). The ANIMO was supported by an educational grant from Boehringer Ingelheim Spain. Dr. Benito-León is supported by NIH R01 NS039422 from the National Institutes of Health, Bethesda, Md., USA.

References

1 Chaudhuri KR, Schapira AH: Non-motor symptoms of Parkinson's disease: dopaminergic pathophysiology and treatment. Lancet Neurol 2009;8:464-474.

2 Aarsland D, Brønnick K, Ehrt U, et al: Neuropsychiatric symptoms in patients with Parkinson's disease and dementia: frequency, profile and associated care giver stress. J Neurol Neurosurg Psychiatry 2007;78:3642 . 
3 Leentjens AF, Dujardin K, Marsh L, et al: Apathy and anhedonia rating scales in Parkinson's disease: critique and recommendations. Mov Disord 2008;23:2004-2014.

$\checkmark 4$ Marin RS: Apathy: a neuropsychiatric syndrome. J Neuropsychiatry Clin Neurosci 1991;3:243-254.

$\checkmark 5$ Pedersen KF, Larsen JP, Alves G, Aarsland D: Prevalence and clinical correlates of apathy in Parkinson's disease: a community-based study. Parkinsonism Relat Disord 2009;15: 295-299.

6 Benito-León J, Cubo E, Coronell C, the ANIMO Study Group: Impact of apathy on health-related quality of life in recently diagnosed Parkinson's disease: the ANIMO study. Mov Disord 2011 Jul 20. doi: 10.1002/ mds. 23872

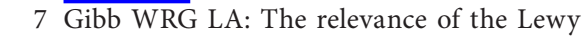
body to the pathogenesis of idiopathic Parkinson's disease. J Neurol Neurosurg Psychiatry $1988 ; 51: 745-752$.

8 American Psychiatric Association: Diagnostic and Statistical Manual of Mental Disorders, ed 4, Text Revision (DSM-IV-TR). Washington, American Psychiatric Association, 2000.

9 Fahn S, Members of the UPDRS Development Committee, Fahn UPsdrsI, S MC, Calne DB, Goldstein M (eds): Recent Developments in Parkinson's Disease. Florham Park, Macmillan Healthcare Information, 1987, pp 153-163.

-10 Hoehn MM, Yahr MD: Parkinsonism: onset, progression and mortality. Neurology 1967; 17:427-442.

-11 Cubo E, Martin PM, Martin-Gonzalez JA, Rodriguez-Blazquez C, Kulisevsky J: Motor laterality asymmetry and nonmotor symptoms in Parkinson's disease. Mov Disord 2010;25:70-75.

-12 Visser M, Marinus J, van Hilten JJ, Schipper RG, Stiggelbout AM: Assessing comorbidity in patients with Parkinson's disease. Mov Disord 2004;19:824-828.
13 First MB SR, Gibbon M, et al: Structured Clinical Interview for DSM-IV-TR Axis I Disorders, Research Version, Patient Edition (SCID-I/P). New York, Biometrics Research, New York State Psychiatric Institute, 2002.

14 Sockeel P, Dujardin K, Devos D, Deneve C, Destee A, Defebvre L: The Lille apathy rating scale (LARS), a new instrument for detecting and quantifying apathy: validation in Parkinson's disease. J Neurol Neurosurg Psychiatry 2006;77:579-584.

-15 Starkstein SE, Mayberg HS, Preziosi TJ, Andrezejewski P, Leiguarda R, Robinson RG: Reliability, validity, and clinical correlates of apathy in Parkinson's disease. J Neuropsychiatry Clin Neurosci 1992;4:134-139.

16 Kulisevsky J, Pagonabarraga J, Pascual-Sedano B, Garcia-Sanchez C, Gironell A: Prevalence and correlates of neuropsychiatric symptoms in Parkinson's disease without dementia. Mov Disord 2008;23:1889-1896.

17 Pedersen KF, Alves G, Bronnick K, Aarsland D, Tysnes OB, Larsen JP: Apathy in drug-naive patients with incident Parkinson's disease: the Norwegian ParkWest study. J Neurol 2010;257:217-223.

18 Barone P, Antonini A, Colosimo C, et al: The PRIAMO study: a multicenter assessment of nonmotor symptoms and their impact on quality of life in Parkinson's disease. Mov Disord 2009;24:1641-1649.

19 Dujardin K, Sockeel P, Devos D, et al: Characteristics of apathy in Parkinson's disease. Mov Disord 2007;22:778-784.

20 Levy ML, Cummings JL, Fairbanks LA, et al: Apathy is not depression. J Neuropsychiatry Clin Neurosci 1998;10:314-319.

21 Oguru M, Tachibana H, Toda K, Okuda B, Oka N: Apathy and depression in Parkinson disease. J Geriatr Psychiatry Neurol 2010;23: 35-41.

22 Rojo A, Aguilar M, Garolera MT, Cubo E, Navas I, Quintana S: Depression in Parkinson's disease: clinical correlates and outcome. Parkinsonism Relat Disord 2003;10:23-28.

-23 Reijnders JS, Ehrt U, Lousberg R, Aarsland $\mathrm{D}$, Leentjens AF: The association between motor subtypes and psychopathology in Parkinson's disease. Parkinsonism Relat Disord 2009;15:379-382.
24 Graham JM, Sagar HJ: A data-driven approach to the study of heterogeneity in idiopathic Parkinson's disease: identification of three distinct subtypes. Mov Disord 1999;14: 10-20.

25 van Rooden SM, Heiser WJ, Kok JN, Verbaan D, van Hilten JJ, Marinus J: The identification of Parkinson's disease subtypes using cluster analysis: a systematic review. Mov Disord 2010;25:969-978.

-26 Cubo E, Martín PM, Martin-Gonzalez JA, Rodríguez-Blázquez C, Kulisevsky J, ELEP Group Members: Motor laterality asymmetry and nonmotor symptoms in Parkinson's disease. Mov Disord 2010;25:70-75.

-27 Amanzio M, Torta DM, Sacco K, Cauda F, D’Agata F, Duca S, et al: Unawareness of deficits in Alzheimer's disease: role of the cingulate cortex. Brain 2011;134:1061-1076.

28 Okiishi CG, Paradiso S, Robinson RG: Gender differences in depression associated with neurologic illness: clinical correlates and pharmacologic response. J Gend Specif Med 2001;4:65-72.

$>29$ Rodriguez-Oroz MC, Jahanshahi M, Krack $\mathrm{P}$, et al: Initial clinical manifestations of Parkinson's disease: features and pathophysiological mechanisms. Lancet Neurol 2009;8: 1128-1139.

-30 Benito-León J, Rivera-Navarro J, Guerrero AL, et al: The CAREQOL-MS was a useful instrument to measure caregiver quality of life in multiple sclerosis. J Clin Epidemiol 2011;64:675-686.

31 Benito-León J, Bermejo-Pareja F, MoralesGonzalez JM, Porta-Etessam J, Trincado R, Vega S, Louis ED: Incidence of Parkinson disease and parkinsonism in three elderly populations of central Spain. Neurology 2004;62:734-741.

\$2 Fayers PM, Curran D, Machin D: Incomplete quality of life data in randomized trials: missing items. Stat Med 1998;15:679-696. 